\title{
Trocas Afetivas de Crianças em Acolhimento Institucional
}

\author{
Stella Rabello Kappler ${ }^{1}$ \\ Deise Maria Leal Fernandes Mendes ${ }^{1}$ \\ ${ }^{1}$ Universidade do Estado do Rio de Janeiro, RJ, Brasil. \\ ${ }^{1}$ Universidade do Estado do Rio de Janeiro, RJ, Brasil.
}

Resumo: Trocas afetivas presentes nas interações com pares e educadores auxiliam a criança institucionalizada a enfrentar o acolhimento, que pode ter como consequência variadas privações. O objetivo desse estudo foi identificar e caracterizar as trocas afetivas e tentativas destas, em contextos de interação criança-criança e criança-educador. Participaram dez crianças, de ambos os sexos, de seis a onze anos e seus educadores. Utilizou-se a técnica do sujeito focal, com observações registradas em vídeo, em situações livres, realizadas em duas instituições de acolhimento. As análises se basearam nas categorias predefinidas de tentativas de trocas afetivas (TTA), trocas afetivas (TA) e comportamentos afetivos. Os resultados revelaram que as TTA foram mais frequentes do que as TA. Houve um percentual de $94 \%$ dos episódios reunindo TTA e TA que se efetivaram entre crianças e seus pares, indicando que estas tentativas e trocas foram bem mais frequentes do que entre crianças e educadores. Dos comportamentos afetivos observados, rir/sorrir foi o que teve a frequência mais elevada $(65,64 \%$ do total de ocorrências). As crianças manifestaram mais comportamentos afetivos em momentos de brincadeira. Com base nas evidências obtidas, entende-se que, ainda que as interações com os educadores sejam mais restritas e ocorram com menos frequência, nas interações com pares as crianças encontram maiores possibilidades de fortalecer os vínculos afetivos formados na instituição, o que pode auxiliá-las a lidar com intercorrências negativas próprias da situação de institucionalização.

Palavras-chave: Trocas Afetivas, Criança, Acolhimento Institucional.

\section{Affective Exchanges of Children in Institutional Care}

\begin{abstract}
Affective exchanges present in the interactions with peers and caregivers help the institutionalized child to face the reception, which can result in various deprivations. The aim of this study was to identify and characterize the affective exchanges and attempts of exchanges, in contexts of interaction child-child and child-caregivers. Ten children of both sexes, from six to eleven, and their caregivers participated. We used the technique of the focal subject, with observations recorded in video, in free situations, performed in two host institutions. The analyses were based on the predefined categories of affective exchanges attempts (AEA), affective exchanges (AE) and affective behaviors. The results revealed that AEA were more frequent than $\mathrm{AE}$. There was a $94 \%$ percentage of the AEA and AE episodes that occurred among children and their peers, indicating that attempts and exchanges were much less frequent among children and caregivers. From the affective behaviors observed, laughing/smiling was the one that had the highest frequency (65.64\% of the total occurrences). Children manifested more affective behavior in moments of play. Based on the evidence obtained, it is understood that, although interactions with caregivers are more restricted and occur less frequently, in interactions with pairs children find greater possibilities to strengthen the affective bonds formed in the institution to deal with negative intercurrences of the situation of institutionalization.
\end{abstract}

Keywords: Affective Exchanges, Child, Institutional Care. 


\title{
Intercambios Afectivos de Niños en Acogida Institucional
}

\begin{abstract}
Resumen: Los intercambios afectivos presentes en las interacciones con pares y educadores ayudan a los niños institucionalizados a enfrentar la acogida, que puede tener como consecuencia variadas privaciones. El objetivo de este estudio fue identificar y caracterizar los cambios afectivos e intentos de éstas, en contextos de interacción niño-niño y niño-educador. Participaron diez niños, de ambos sexos, de seis a once años y sus educadores. Se utilizó la técnica del sujeto focal, con observaciones registradas en video, en situaciones libres, realizadas en dos instituciones de acogida. Los análisis se basaron en las categorías predefinidas de intentos de intercambios afectivos (IIA), los cambios afectivos (IA) y los comportamientos afectivos. Los resultados revelaron que las IIA fueron más frecuentes que las IA. Hubo un porcentaje del $94 \%$ de los episodios reuniendo IIA y IA que se realizaron entre niños y sus pares, indicando que estos intentos e intercambios fueron mucho más frecuentes que entre niños y educadores. De los comportamientos afectivos observados, reír/sonreír fue el que tuvo la frecuencia más elevada (65,64\% del total de ocurrencias). Los niños manifestaron más comportamientos afectivos en momentos de broma. Con base en las evidencias obtenidas, se entiende que, aunque las interacciones con los educadores son más restringidas y ocurren con menos frecuencia, en las interacciones con pares los niños encuentran mayores posibilidades de fortalecer los vínculos afectivos formados en la institución, lo que puede auxiliarlas a lidiar con intercurrencias negativas propias de la situación de institucionalización.
\end{abstract}

Palabras clave: Intercambios Afectivos, Niños, Acogida Institucional.

Ao nascer, o indivíduo demonstra uma motivação para detectar contingências e para experimentar calor emocional (Keller, 2007). Mesmo com capacidades de comunicação ainda limitadas, com alguns dias de vida os bebês já são capazes de expressar uma sensibilidade social como, por exemplo, dar preferência a vozes e faces humanas em detrimento de outro som ou objeto qualquer, e discriminar o rosto da mãe ao dar mais atenção para o dela do que para o de uma pessoa estranha. As interações entre pais/cuidador e o bebê vão evoluindo e se tornando mais complexas à medida que a criança cresce (Seidl-de-Moura, \& Ribas, 2004).

As trocas afetivas estabelecidas nesse período inicial com os cuidadores serão fundamentais não só para as interações do indivíduo com outras pessoas, contribuindo para seu desenvolvimento global, mas mesmo particularmente relevantes para o desenvolvimento cerebral (Gerhardt, 2004). Isto se deve ao fato de que o cérebro continua se desenvolvendo após o nascimento e os sistemas neurais vão se adaptando às características e exigências do ambiente em que o indivíduo está inserido, o que inclui o social.

Um olhar para a questão das relações de gênero na produção de trocas afetivas e suas implicações merece atenção especial ao pensar o exercício da parentalidade. No âmbito familiar, a afetividade começa a ser experimentada através das interações iniciais mantidas especialmente com os pais, e diferenças entre os papéis sociais de pai e mãe, precisam ser consideradas. Embora estivesse presente em diversas partes do mundo, incluindo o Brasil, uma delimitação clara de modelos nas relações de gênero e familiares, segundo a qual ao "homem provedor financeiro corresponde uma mulher naturalmente afetiva e maternal" (Lyra, \& Medrado, 2000, p. 145), transformações importantes parecem estar em curso nas últimas décadas. Pesquisas mais recentes derrubam estereótipos de um pai frio que não manifesta afeto por seus filhos (Perucchi, \& Beirão, 2007) e aponta para novos formatos de ser exercida a paternidade e a maternidade, e de se cuidar dos filhos e lidar com o afeto.

Em um ambiente de cuidados coletivos, a forma de cuidar é diferente do ambiente familiar em que a mãe/pai ou cuidador principal exerce uma atenção mais individualizada à criança. Alguns autores afirmam que crianças que vivem em ambiente institucional não recebem o carinho e estímulo necessários para um crescimento e desenvolvimento psicológico saudável (Ijzendoorn et al., 2011). Ressalta-se, no 
entanto, a marcante escassez de estudos com foco na afetividade em crianças acolhidas, que promovam uma discussão a respeito e contribuam para avanços nas reflexões acerca das questões envolvidas.

Também nesse contexto de desenvolvimento, e como salientam Pessoa e Costa (2014), é a partir da expressividade e das interações que a criança vai se diferenciando e construindo a sua individualidade e identidade. Os educadores são responsáveis pela organização de condições que favoreçam esse processo de formação da identidade, que perpassa e inclui a questão de gênero (Cecílio, Borges, \& Scorsolini-Comin, 2018). Tendo nesses profissionais um modelo de referência, a criança experimenta assumir distintos papéis, como o de ser menino ou menina.

Quando as crianças são encaminhadas para acolhimento institucional, elas acabam perdendo parte de sua identidade e não há o rompimento apenas dos vínculos com a sua família de origem, mas também com vizinhos e com a comunidade em que viviam (Calcing, \& Benetti, 2014; Corrêa, \& Cavalcante, 2013). Nesse momento, ocorre uma transição em que princípios e valores adquiridos anteriormente passam por transformações e há novas regras a serem adquiridas em um ambiente de cuidados coletivos. Ainda que seja respeitada a individualidade da criança e que ela mantenha alguns objetos de uso pessoal, como roupas, muita coisa passa a ser compartilhada, como o quarto e os brinquedos.

Além disso, por se tratar de uma instituição, é comum que as decisões sejam tomadas levando-se em consideração o grupo e não somente um indivíduo em particular e, por isso, muitas vezes, as crianças são impedidas de fazerem escolhas pessoais (Magalhães, Costa, \& Cavalcante, 2011). Na contramão desses resultados indicativos de prejuízos causados pelo acolhimento, alguns estudos (Belsky, \& Haan, 2011) realizados em orfanatos, mostraram respostas diferenciadas em crianças expostas às mesmas condições consideradas como não adequadas para um desenvolvimento cerebral e psicológico apropriado. Algumas crianças parecem enfrentar e reagir a condições desfavoráveis com menor dificuldade do que outras, demonstrando resiliência.

O afastamento da criança de sua família natural certamente pode ser considerado um fator prejudicial para o desenvolvimento. No entanto, há que se levar em conta também os casos em que as crianças são negligenciadas, sofrem algum tipo de abuso físico, psicológico ou sexual por parte de sua família, por exemplo, e nestes a institucionalização pode ser considerada um fator de proteção.

A par das adversidades que o indivíduo institucionalizado enfrenta, a instituição de acolhimento também pode apresentar aspectos protetivos e promotores de bem-estar, como as possibilidades de construção de novos vínculos afetivos com pares, educadores sociais e demais funcionários. As interações sociais e trocas de afetos estabelecidas poderão cumprir um papel da maior relevância para o desenvolvimento, suprindo, em parte, a falta de convivência com a família natural. O relacionamento afetivo de crianças com quem assume responsabilidades por sua criação e cuidados primários, ainda que não sejam os pais, é fundamental para o seu desenvolvimento.

Outro importante caminho de interações estabelecidas por crianças acolhidas é o estabelecido com pares. As trocas afetivas ocorridas podem auxiliar a criança a enfrentar o acolhimento com suas variadas consequências e importantes privações. Maia e Williams (2005) destacaram esse tipo de relacionamento como um dos mais importantes fatores de proteção para criança, visto que a proximidade com outras crianças institucionalizadas a ajudam a desenvolver estratégias para o enfrentamento de adversidades. As trocas afetivas entre crianças institucionalizadas podem ser consideradas também como um fator de proteção, pois possibilitam o compartilhamento de experiências, sentimentos e afetos positivos e negativos (Siqueira, \& Dell'Aglio, 2006). O indivíduo pode demonstrar resiliência, enfrentando de maneira positiva a sua nova realidade de institucionalização (Barros \& Fiamenghi Jr., 2007). Além disso, o apoio emocional recebido de outros indivíduos que vivem em situação semelhante à sua, pode contribuir para a qualidade de vida e para o seu bem-estar (Siqueira, \& Dell'Aglio, 2006).

Por se tratar de um ambiente coletivo, no entanto, é esperado que haja além de amizades e relações positivas, também disputas e comportamentos agressivos. Tal questão foi levantada em uma pesquisa realizada por Barros e Fiamenghi Jr. (2007) que tinha como objetivo observar interações estabelecidas entre crianças e entre estas e suas educadoras sociais. Foram observadas crianças com idades entre dez meses a cinco anos e nove meses, de ambos os sexos, de uma cidade do interior do estado de São Paulo. 
Os autores (Barros \& Fiamenghi Jr., 2007) relataram que a maioria das crianças institucionalizadas sofreu negligência e/ou maus-tratos por parte de seus pais biológicos. Essa evidência reforça a hipótese de que os comportamentos agressivos manifestados pelas crianças em instituições de acolhimento podem estar relacionados ao tratamento que tinham quando viviam com seus pais e familiares. Os autores acreditam que algumas crianças ainda não desenvolveram estratégias que poderiam auxiliá-las no enfrentamento de situações provenientes de um ambiente agressivo. Muitas vezes, a criança não encontra outro modo para se expressar que não seja da forma como está acostumada, reproduzindo padrões comportamentais a que estava habituada, o que pode significar que o faça através de gritos, utilizando palavrões e/ou agredindo outras pessoas verbalmente ou fisicamente.

Os comportamentos agressivos, que podem ser provenientes de relações que a criança estabeleceu antes de ser institucionalizada, podem acabar sendo reforçados na instituição. É possível conjecturar-se que se as educadoras que cuidam das crianças também as tratarem de forma rígida e agressiva haverá um reforço, na visão da criança, de que a figura de cuidado também cuida sendo agressiva (Barros \& Fiamenghi Jr., 2007).

Dentre os funcionários, os educadores têm uma presença mais acentuada na rotina das crianças, visto que são responsáveis pelo atendimento às suas necessidades, desde as mais básicas. São eles que dão o almoço, encaminham para o banho, acordam as crianças pela manhã e as ajudam nas tarefas escolares. O educador social pode ser considerado uma figura de referência e seu trabalho deve ir além de auxiliar e direcionar as crianças para atividades rotineiras. Siqueira e Dell'Aglio (2006) argumentam que as relações estabelecidas com as figuras de cuidado têm papel central na vida da criança. Todavia, Alexandre e Vieira (2004) afirmam que devido à alta relação de crianças institucionalizadas por educador, o afeto dos educadores sociais tem que ser dividido. Sendo assim, é preciso que esses profissionais se empenhem em atender com mais individualidade as crianças, estando conscientes da importância de sua atuação junto a elas e da afetividade.

A partir do exposto e ressaltando a importância do estabelecimento de trocas afetivas para um desenvolvimento saudável, esse estudo teve como principal objetivo identificar e caracterizar as trocas afetivas e tentativas de trocas afetivas, em contextos de interação criança-criança e criança-educador, para crianças que vivem em instituições de acolhimento.

\section{Método}

\section{Participantes}

Fizeram parte desse estudo dez crianças, de ambos os sexos, com idades de seis a onze anos, institucionalizadas em duas instituições de acolhimento, do município de Petrópolis (região serrana do Rio de Janeiro) e seis educadores sociais que eram responsáveis pelos cuidados das crianças participantes. A média das idades das crianças foi de oito anos e meio (DP $=1,84)$, sendo $80 \%$ da amostra composta pelo sexo masculino. Todos frequentavam escolas e estavam cursando o ensino fundamental.

As crianças participantes da pesquisa foram encaminhadas para as instituições pela Vara da Infância, Juventude e do Idoso por motivo de negligência familiar. O tempo de acolhimento variou de nove a vinte meses, com uma média de doze meses $(\mathrm{DP}=$ $4,47)$. A maioria das crianças $(80,0 \%)$ recebia visita da mãe, acompanhada pelo pai $(62,5 \%)$ ou pelo padrasto $(37,5 \%)$. Todos conviviam com seus irmãos, pois haviam sido institucionalizados de forma coletiva. Metade da amostra (50,0\%) também tinha irmãos vivendo em outras instituições de acolhimento. Isto se devia ao fato de serem adolescentes com idade superior a 12 anos e que, por esse motivo, não podiam residir na mesma instituição.

Com relação aos educadores, fizeram parte do estudo aqueles que eram responsáveis pelos cuidados das crianças participantes. A média de idade desses profissionais foi de 47 anos ( $M=47$; $D P=10,64)$, sendo que o mais novo tinha 33 anos de idade e o mais velho 59 anos. A maioria dos participantes era do sexo feminino (83,3\%) e apenas $16,7 \%$ eram do sexo masculino. A média do tempo que atuavam na instituição foi de oito anos ( $\mathrm{M}=8,17$; $\mathrm{DP}=5,56)$.

\section{Ambiente}

A pesquisa foi realizada em duas instituições de acolhimento do município de Petrópolis. Ambas receberam uma designação por código para que fosse mantido sigilo. A instituição C.C. recebe meninas, na faixa etária de zero a catorze anos e, excepcionalmente, meninos quando os mesmos vêm acompanhados de 
suas irmãs. Já a instituição L.C., recebe crianças de ambos os sexos, na faixa etária de zero a 12 anos.

As instituições de acolhimento apresentam características de rotina e funcionamento semelhantes, funcionando em regime integral e atendendo a crianças e adolescentes, encaminhadas pela Vara da Infância, Juventude e do Idoso, que se encontram em situação de risco ou vulnerabilidade social, que variam de negligência, abandono familiar, violência física ou sexual, exploração sexual, dentre outros.

No tocante às características físicas, as duas instituições são bem diferentes. A instituição L.C. tem um espaço maior e fica localizada em uma propriedade com três casas construídas e uma ampla área externa. Diferentemente, a instituição C.C. funciona em um prédio de dois andares, com apenas uma pequena área aberta. Pode-se pensar que por dispor de um espaço físico menor, acaba favorecendo a convivência dos institucionalizados, na medida em que permite uma maior interação entre eles.

\section{Instrumentos}

Foram utilizados, tanto para as crianças quanto para os educadores, fichas de identificação para preenchimento dos dados sociodemográficos e formulários de informações complementares. Ademais, ficha de caracterização para os dados da instituição, ficha de registro das sessões de vídeogravação e um diário de campo em que foram registradas falas e outras observações da pesquisadora.

\section{Categorias de observação}

Foram predefinidas categorias relativas às trocas afetivas, tentativas de trocas afetivas, bem como para comportamentos afetivos, com as seguintes definições operacionais:

1. Tentativa de estabelecimento de troca afetiva (TTA): tentativa de alguém de se envolver com outro alguém em uma troca afetiva sem, contudo, que a troca se efetive, considerando que a tentativa se dá quando: o sujeito focal manifesta um comportamento afetivo dirigido a outra criança ou a um de seus educadores (destinatário) ou quando o sujeito focal é alvo (destinatário) de um comportamento afetivo emitido por outra criança ou por um de seus educadores e não há resposta do destinatário sob a forma de comportamento afetivo.
2. Troca afetiva (TA): troca de afeto entre duas crianças ou entre uma criança e educador que se dá quando uma tentativa de troca afetiva se desdobra, resultando em uma resposta do destinatário sob a forma de um comportamento afetivo.

3. Comportamentos afetivos: comportamentos considerados como manifestações de afeto que incluíram as seguintes subcategorias:

a) Abraçar: envolver com os braços uma pessoa que esteja de frente, de lado ou de costas para aquele que pratica a ação. As mãos podem ficar apoiadas nas costas, peito ou braços do outro, por exemplo. Também pode ocorrer de a cabeça se apoiar junto ao corpo do outro.

b) Acariciar: fazer carinho utilizando movimentos com a mão ou outra parte do corpo sobre a superfície do corpo do outro, alisando, afagando outra pessoa (exemplo: esfregar a cabeça no ombro, passar a mão na cabeça etc.).

c) Agredir através de gestos: agressão manifestada através de gestos. $\mathrm{O}$ indivíduo emite gestos com caráter ofensivo dirigido a outra pessoa. Pode ser caracterizado como virar as costas para alguém, dar de ombros e mostrar a língua, por exemplo (adaptado de Cavalcante, 2008).

d) Agredir fisicamente: agressão manifestada de forma física, com a presença de um comportamento hostil em que um indivíduo confere dano ou causa prejuízo à outra pessoa, que pode ocorrer das seguintes formas: 1) utilizando alguma parte do seu corpo (ex.: tapas, mordidas, beliscões, empurrões e chutes) ou 2) utilizando algum objeto para atingir o outro com o uso de força (adaptado de Cavalcante, 2008).

e) Agredir verbalmente: agressão manifestada de forma verbal, com a presença de insultos, xingamentos ou ofensas utilizando palavras com conotação ofensiva para denegrir alguém (exemplo: Você é feio! Você é fedorento!) (adaptado de Cavalcante, 2008).

f) Beijar: projeção e contração dos lábios de alguém fazendo contato com alguma parte do corpo de outra pessoa.

g) Chorar: produzir lágrimas acompanhadas de expressão facial, dirigida à outra pessoa, em que haja uma contração dos olhos, projeção dos lábios (bico) ou abertura da boca. Pode vir acompanhado de sons e soluços, parecendo comunicar estado de tristeza ou desconforto. 
h) Consolar verbalmente: manifestação verbal de um indivíduo que tem como objetivo confortar outra pessoa. É expressa através de palavras ou frases que tenham conteúdo afetivo positivo (exemplo: Não chore, vai passar).

i) Elogiar: expressão verbal com conotação positiva, utilizada para enaltecer alguém. Pode ser usada para realçar uma característica ou comportamento de alguém (ex.: Você é/está bonita!), bem como para motivar uma pessoa (exemplo: Você está indo muito bem no exercício!).

j) Gritar de alegria: manifestar conteúdo positivo, dirigido à outra pessoa, em que o indivíduo produz um som alto, comunicando um estado de alegria e empolgação.

k) Falar ou gritar conteúdo negativo: manifestar conteúdo negativo, dirigido à outra pessoa, associado a uma situação de descontentamento e/ ou reclamação, em que o indivíduo pode elevar o tom da sua voz. Diferentemente da agressão verbal, nessa categoria o indivíduo não utiliza insultos ou ofensas (exemplo: quando o indivíduo pede para o outro parar de praticar uma ação utilizando frases do tipo "Para com isso que já está me enchendo", "Sai daqui", "Não quero mais saber de você" etc.).

l) Fazer cara de raiva/zangado(a): expressão facial, dirigida a outra pessoa, em que se observa sobrancelhas caídas, enrugamento acentuado da testa, olhos cerrados, contração da raiz das narinas, dilatação das narinas, boca cerrada ou com os dentes presos e contração do queixo.

m) Rir/Sorrir: manifestar expressão facial, dirigida a outra pessoa, que implica necessariamente a extensão dos lábios com elevação dos cantos da boca. Adicionalmente a esse movimento, pode também estar presente a abertura de boca e/ou elevação de bochechas, e/ou fechamento (total ou parcial) dos olhos com a presença ou não de sons (Os episódios em que se ouve riso emitido pelo sujeito focal ou a ele dirigido, ainda que não apareça na imagem, são marcados, e sua duração em número de intervalos determinada pelo tempo em que permanece audível) (adaptado de Mendes, \& Seidl-de-Moura, 2009).

n) Ausência de comportamento afetivo: o indivíduo não manifesta comportamento afetivo em reação ao comportamento afetivo direcionado a ele.

\section{Procedimentos}

Por se tratarem de crianças institucionalizadas, foi apresentado aos responsáveis pelas instituições de acolhimento o projeto de pesquisa explicitando-se seus objetivos e relevância do mesmo. Após autorização por escrito de ambas, o projeto foi submetido e avaliado pelo Comitê de Ética em Pesquisa da Universidade do Estado do Rio de Janeiro (CEP-UERJ) tendo sido aprovado através de parecer consubstanciado ( $\left.{ }^{\circ} 1.768 .650\right)$.

Após a aprovação, a coleta teve início e os responsáveis pelas instituições e os educadores sociais assinaram, inicialmente, o Termo de Consentimento Livre e Esclarecido (TCLE) e a Autorização para Uso de Imagens de Vídeo. Em seguida, foram preenchidas as fichas de identificação e formulário de informações complementares de cada criança, além das fichas de caracterização das instituições, com auxílio das psicólogas das instituições. Os dados dos educadores foram solicitados diretamente a eles.

A técnica de coleta de dados utilizada nesse estudo foi a de sujeito focal (SF) (Altmann, 1974), com observação naturalística e registro em vídeo. Antes do início das filmagens, foi realizado um estudo-piloto, com duas visitas às instituições, para a testagem das categorias e para que as crianças e funcionários das instituições pudessem se acostumar com a presença da pesquisadora e da filmadora. A ordem de observação das crianças não seguiu critério predefinido e se deu de forma aleatória. Foram realizadas dez sessões de observação com filmagem por SF, ao longo de dez semanas, tendo sido os SF filmados apenas uma vez por observação. Dois dos SF estavam em vias de retornarem à família e, por isso, ficaram com uma sessão a menos, pois no dia agendado para a última sessão eles já não se encontravam mais na instituição.

Para a redução dos dados, todas as sessões foram assistidas na íntegra, tantas vezes quantas necessário, e identificados os episódios de TTA e TA entre sujeito-focal-criança e sujeito-focal-educador, assim como as subcategorias de comportamentos afetivos envolvidos. Todas as informações definidas para caraterização de cada episódio de TTA e TA, e dos comportamentos afetivos envolvidos foram anotadas na ficha de registro das sessões de observação/filmagem. Posteriormente, os dados foram digitados no software SPSS (Statistical Package for Social Sciences), versão 20.0, utilizado para o processamento das análises.

Foram realizadas análises quantitativas, através de estatística descritiva, para a caracterização socio- 
demográfica dos participantes e dos episódios de TTA e TA, com cálculos de frequências, percentuais, médias e desvio-padrão.

\section{Resultados e discussão}

Ao longo das sessões de observação/filmagem, foram identificados, ao todo, 398 episódios de TTA e TA, sendo que as TTA foram mais frequentes $(70,4 \%)$, enquanto as TA, que implicavam, necessariamente, a promoção de um comportamento afetivo e uma resposta do destinatário em forma de comportamento afetivo, ocorreram em $29,6 \%$ do total de episódios identificados.

A maior parte das TTA e TA ocorreu entre as crianças e seus pares (94\%). Houve $94 \%$ de TTA de crianças com seus pares e apenas $6 \%$ de crianças com seus educadores. As TA atingiram o percentual de $93 \%$ das crianças com seus pares e $7 \%$ das crianças com educadores. Nas sessões de observação/filmagem, os SF estavam sempre próximos de outras crianças e, quase sempre, envolvidos nas mesmas atividades, o que pode ter favorecido suas trocas e esses resultados. Já no que se refere aos educadores, era mais comum se manterem relativamente distantes das crianças em boa parte das atividades durante as observações. Nas observações realizadas no pátio das instituições, por exemplo, normalmente os educadores ficavam conversando entre si em um lugar mais afastado, enquanto as crianças brincavam e, também por esse motivo, possivelmente, as trocas afetivas entre a díade criança-educador eram mais difíceis de ocorrer. De acordo com Barros \& Fiamenghi Jr., 2007, crianças institucionalizadas devem estabelecer uma forte e constante vinculação afetiva com os cuidadores substitutos, principalmente porque elas já estão afastadas de pessoas com quem tinham um vínculo e, portanto, acredita-se que sofram com isso.

Ainda que estudos como o mencionado ressaltem a relevância desses profissionais para o desenvolvimento das crianças institucionalizadas, as normas comumente estabelecidas para serviços de acolhimento não parecem ir na direção do favorecimento de trocas afetivas. Definem como possível uma proporção entre o número de educadores e o de crianças que é alta (um cuidador para cada dez crianças, diferentemente do que ocorre na maioria das famílias), dificultando uma atenção mais individualizada (Alexandre, \&Vieira, 2004) e maior aproximação emocional com cada uma.

Pode-se também discutir os resultados acerca das TTA e TA entre crianças e educadores em termos das relações de gênero e dinâmica entre educadores(as) e meninos(as). Causou estranheza o baixo índice de trocas envolvendo adultos e crianças, sobretudo tendo em vista serem cinco mulheres em seis educadores participantes. Pode-se especular que o perfil de educadora, de modo distinto ao que era usualmente esperado de um modelo feminino, pode estar refletindo as mudanças discutidas por Perucchi e Beirão (2007) e não corresponderem tanto mais ao de "mulher afetiva e maternal" (Lyra, \& Medrado, 2000). Observa-se ainda que das dez crianças, oito eram meninos e em uma fase importante no processo de formação da identidade, incluindo a questão de gênero como discutido por Cecílio, Borges e Scorsolini-Comin (2018).

Levando-se em conta o que foi observado, mas com o necessário cuidado com as possíveis especulações, pode-se considerar que mesmo que as crianças não criem uma vinculação afetiva forte com os educadores sociais, as outras crianças que estão acolhidas também se tornam possibilidades importantes de vinculação e trocas afetivas.

Com isso, pode-se pensar que as crianças se dirigem, em maior proporção a seus pares ao buscar interagir com afetividade e promover uma tentativa de troca afetiva. Resultados obtidos por Alexandre e Vieira (2004) revelaram que na ausência de uma figura de cuidado que seja significativa para a criança, a mesma tende a formar relações de apego com as outras. Ainda que não seja exatamente esse o caso do estudo aqui relatado, já que os educadores estavam presentes no cotidiano das crianças e em episódios de TTA ou TA, o relato dos autores pode ser apropriado como indicativo do que se deseja argumentar.

Como pode ser visualizado no Gráfico 1, as crianças interagiram entre si na maior parte dos casos quando estavam brincando, sendo essa situação a que apresentou mais ocorrências de TTA (34\% de todas as TTA) e TA (38\% de todas as TA). Este resultado vai ao encontro do que indicam Corrêa e Cavalcante (2013) sobre a brincadeira como sendo um dos momentos de interação entre díades criança-criança que acabam fortalecendo as trocas afetivas. A brincadeira permite que a criança crie e explore um mundo de fantasia que é influenciado por situações que ela vive na sua rotina diária e promove a oportunidade de manifestar seus afetos positivos e negativos em relação a quem está interagindo com ela. Outras situações em que a criança esteja focada em uma atividade, como assistindo a um filme ou lendo uma história, podem não possibilitar as TTA e TA com tanta frequência. 
Depois de brincadeira, as situações em que houve mais ocorrências de TA e TTA, foram as de atividade livre (TTA $=23 \%$ de todas as TTA; $\mathrm{TA}=21 \%$ de todas as TA), quando o SF estava olhando uma revista ou apenas sentado no sofá conversando com outra criança, o almoço (TTA $=20 \%$ de todas as TTA; TA, $14 \%$ de todas as TA) e assistir à televisão (TTA $=13 \%$ de todas as TTA; TA $=8 \%$ de todas as TA). Outras situações como a realização de tarefas escolares, tarefas gerais que envolviam a limpeza da casa ou a lavagem da louça, dentre outras, totalizaram $15 \%$ de todas as
TTA e $14 \%$ de todas as TA. Apesar de cerca de $10 \%$ (do total de ocorrências) de TTA e TA terem ocorrido quando os sujeitos focais foram filmados assistindo televisão, cabe ressaltar que nos momentos em que estavam nessa atividade as crianças ficavam tão concentradas no que estavam vendo que passavam muito tempo sentadas no sofá sem interagir com os demais indivíduos que estavam no mesmo local.

Já com relação ao ambiente físico, pode-se verificar através do Gráfico 2 que a sala em que ficava posta a televisão foi o que contou com a maior parte

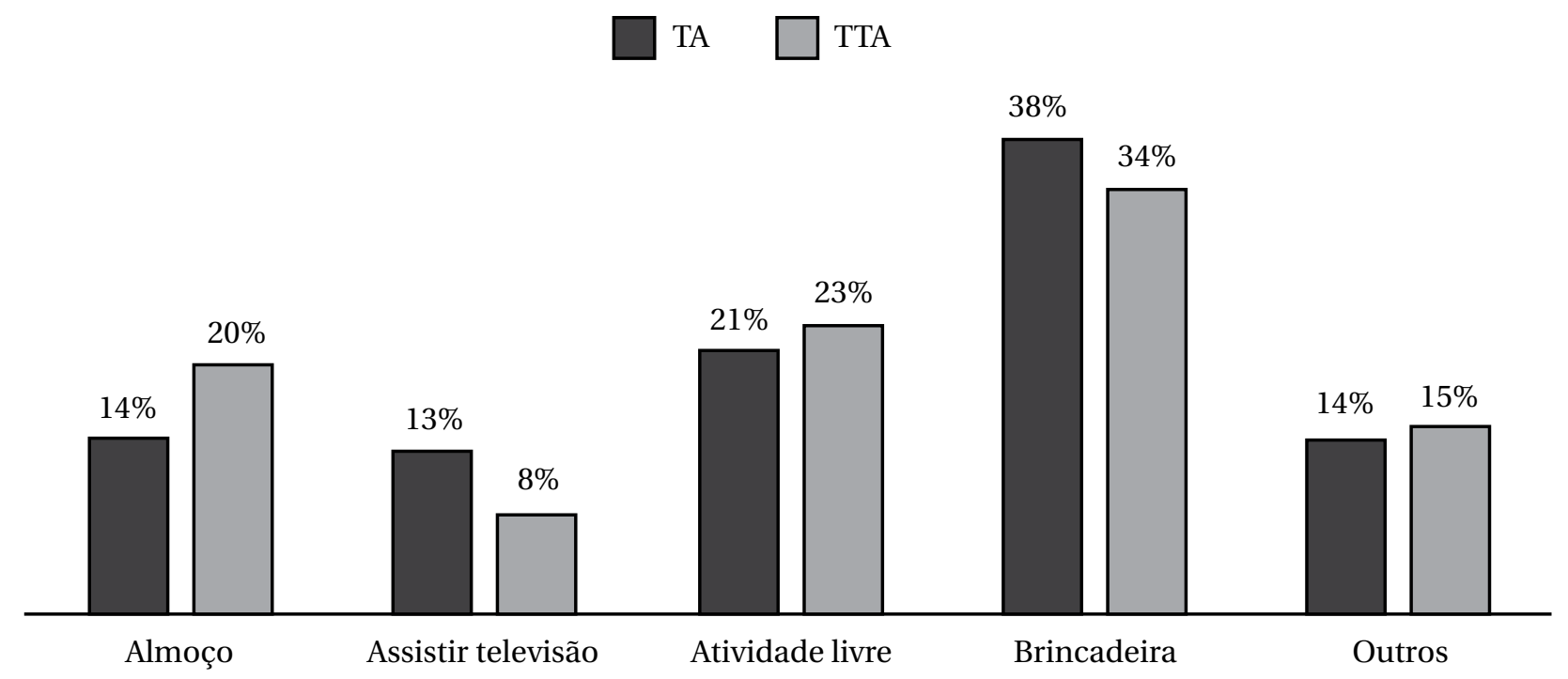

Gráfico 1

Tentativas e trocas afetivas distribuídas por situação em que se inseriram.

TA

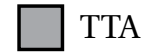

$39 \%$

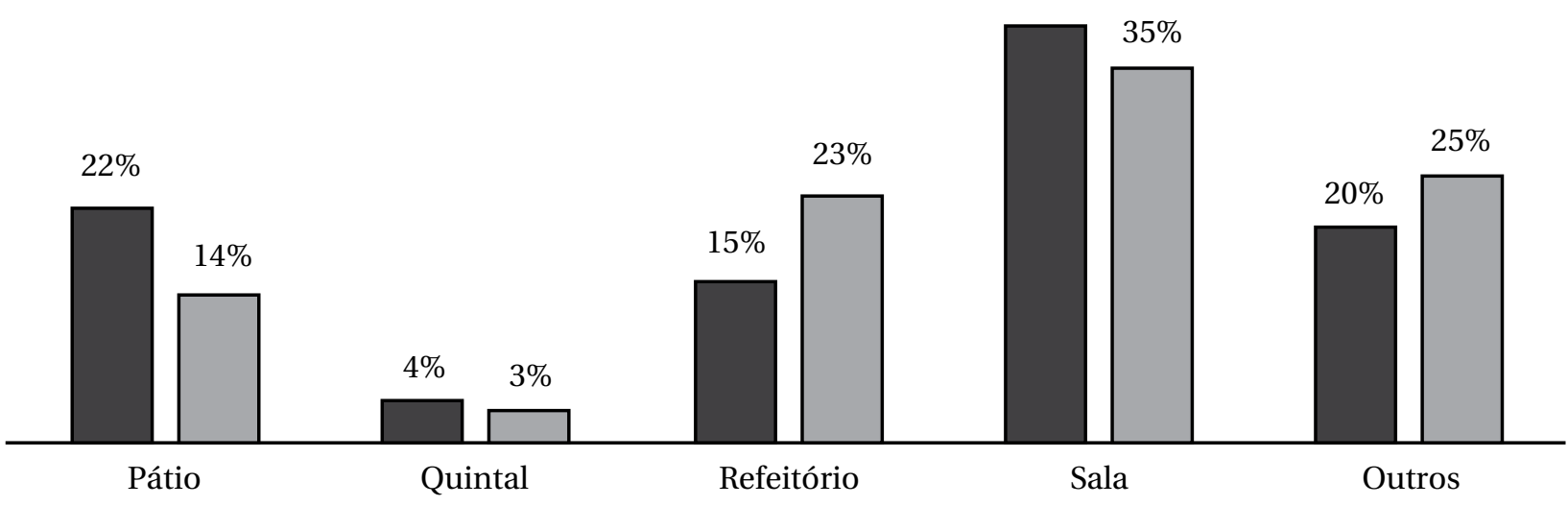

Gráfico 2

Percentuais de tentativas e de trocas afetivas distribuídas por ambiente físico. 
de registros de comportamentos afetivos nas duas instituições (37\%). Em certa medida, talvez isso tenha se devido ao fato de que, geralmente, nos horários em que a pesquisadora chegava à instituição, era comum que as crianças estivessem na sala brincando ou conversando, situações que parecem propiciar trocas afetivas.

O refeitório também foi um lugar em que foram registradas algumas TTA (23\%) e TA (15\%), pois na hora do almoço havia a reunião das crianças que estavam se preparando para ir para a escola com aquelas que estavam chegando à casa e que haviam estudado no turno da manhã. Com isso, conversas e interações entre elas ocorriam o que acabava por se constituir em situação em que as trocas ou tentativas se estabeleciam. Durante o almoço, houve muitas trocas afetivas entre as crianças e observou-se que os educadores se faziam mais presentes, orientando a distribuição da comida e através de discurso que envolvia práticas educativas a respeito de como as crianças deveriam se sentar e que deveriam evitar a conversa na hora da refeição, por exemplo. Isso favorecia interações com os educadores em que tentativas e trocas poderiam se concretizar, mas não ocorreu em grande medida.

Houve no pátio $22 \%$ de TA e $14 \%$ de TTA e no quintal $4 \%$ de TA e $3 \%$ de TTA, aonde se poderia esperar percentuais maiores por serem lugares para brincadeiras que, como apontam Corrêa e Cavalcante (2013), fortalecem trocas afetivas. Já as demais ocorrências, aconteceram em locais em que nem sempre as crianças eram filmadas como sala de atividades educacionais, cozinha e/ou banheiro (23\%).

Para fins de análise comparativa entre diferentes faixas etárias, os SF foram divididos em dois grupos, a saber: o Grupo 1, com os SF com idade de seis a oito anos $(\mathrm{n}=5)$ e o Grupo 2 com os que tinham idade entre nove e onze anos $(n=5)$. No primeiro grupo, e considerando o total de episódios em todas as sessões, houve $61 \%$ de TTA e $75 \%$ de TA, enquanto no Grupo 2 , em que estavam as crianças mais velhas, os percentuais foram bem mais baixos, de apenas $39 \%$ em TTA e $25 \%$ em TA. De acordo com esses percentuais, as crianças mais novas participaram de mais episódios com a manifestação de comportamentos afetivos. Pode-se especular que crianças mais velhas não se sintam tão à vontade, ou tenham tanta necessidade, para trocas afetivas. O que pode ser um resultado que não difira tanto do que ocorre com crianças que vivam com suas famílias naturais. Cabe, no entanto, voltar a mencionar a questão discutida anteriormente quanto à fase do desenvolvimento em que se encontram e o fato de serem em sua maioria meninos. Talvez os mais velhos, em especial, não considerem que demonstrações afetivas sejam adequadas ao papel masculino.

Houve pouca diferença quando os grupos foram comparados com relação às ocorrências de TTA e TA com pares e educadores. Com relação às TA, no Grupo 1, houve $91 \%$ de todas as TA com pares $\mathrm{e}$ $9 \%$ com educadores, mas, no Grupo 2, 100\% foram de TA com pares e, portanto, nenhuma TA com educadores, o que pode estar na direção do argumento acima. No que se refere às TTA, o Grupo 1 apresentou 93\% com pares e $7 \%$ com educadores. No Grupo 2, 96\% das TTA foram com pares e $4 \%$ com educadores. Esses resultados indicaram que o Grupo 2 estabeleceu mais tentativas de trocas com pares do que o Grupo 1 e, por conseguinte, o Grupo 1 estabeleceu mais tentativas com educadores se comparado ao Grupo 2, ou seja, as crianças mais velhas tinham mais TTA com pares do que as mais novas. Conclui-se, portanto, que as crianças mais velhas estão mais envolvidas em episódios de TTA e TA com seus pares, enquanto as crianças mais novas, apesar de interagirem mais com pares do que com educadores, envolveram-se com mais frequência, também, em alguma medida, em episódios de TTA TA com esses profissionais. Os resultados encontrados com relação à duração das TTA e TA revelaram que, no que se refere às trocas afetivas com pares no Grupo 1, a média encontrada foi de 62 segundos de duração ( $\mathrm{DP}=55,69$ ), já com o Grupo 2 , a média foi de 20 segundos $(D P=13,65)$. As trocas afetivas com os educadores no Grupo 1 tiveram uma média de duração de oito segundos ( $\mathrm{DP}=10,83)$, enquanto o Grupo 2 não teve nenhuma TA registrada com educadores.

Nas TTA com pares, o Grupo 1 também teve uma duração maior, registrando uma média de 77 segundos de duração ( $\mathrm{DP}=24,30$ ), ao passo que o Grupo 2 apresentou uma duração média de 50 segundos ( $\mathrm{DP}=16,77$ ). $\mathrm{O}$ que se constatou sobre as TTA com os educadores não foi diferente e o Grupo 1 mostrou uma duração média maior, de sete segundos ( $\mathrm{DP}=5,03)$, ao mesmo tempo em que o Grupo 2 teve uma média de duração de um segundo e meio (DP = 1,14).

Com relação aos comportamentos afetivos emitidos, foi encontrado um total de 553 ocorrências, sendo $71 \%$ de valoração positiva e $29 \%$ negativa. Pôde ser observado um número elevado de manifestações afetivas do tipo rir/sorrir $(65,64 \%)$, seguido por falar 
ou gritar conteúdo negativo (11,75\%), agredir verbalmente $(6,51 \%)$ e agredir fisicamente $(6,15 \%)$. Já as categorias menos observadas foram elogiar $(0,54 \%)$, chorar $(0,18 \%)$ e consolar verbalmente $(0,20 \%)$. Não foi observada, nas filmagens, nenhuma ocorrência para a categoria beijar, como descrito na Tabela.

Pouco contato físico pôde ser observado entre as crianças e seus pares. O comportamento de abraçar, por exemplo, foi manifestado em apenas 1,08\% das observações entre crianças e em momentos em que elas estavam comemorando algum fato. Já o comportamento acariciar, pôde ser observado também nas interações entre crianças com seus educadores apesar, de constarem no diário de campo descrições de um contato quase que predominantemente verbal entre essa díade. Nos diálogos estabelecidos durantes as carícias, nota-se que o educador fala de forma afetuosa com o SF, dando atenção ao que ele estava falando. Portanto, percebe-se que ainda que as TA entre as díades criança-educador não tenham sido tão frequentes, elas ocorreram e podem ter sido importantes para ambos.

Os diálogos presentes junto a comportamentos tomados como expressões positivas, como consolar verbalmente (presente em $0,20 \%$ das ocorrências de TTA e TA), e gritar de alegria (presente em $0,72 \%$ das ocorrências de TTA e TA), também ocorreram com baixa frequência e somente entre as crianças e seus pares. Isto também ocorreu no que diz respeito ao comportamento de abraçar, em que as crianças gritavam de alegria em situações de comemoração por terem conseguido atingir um objetivo, como por exemplo, fazer um gol enquanto estavam jogando futebol. Por outro lado, os comportamentos associados a diálogos de cunho negativo, como agredir verbalmente e falar ou gritar conteúdo negativo, ocorreram tanto entre as crianças, quanto entre elas e os educadores. No segundo caso, os resultados obtidos indicaram que em grande parte das vezes foram manifestados em situações que envolviam práticas educativas dos educadores. Em alguns casos, esses profissionais dirigiam-se de forma ríspida às crianças enquanto os estava orientando a como se sentar à mesa ou como deveriam guardar seus pertences pessoais no armário, por exemplo.

Para situações desse tipo, a literatura discute que práticas que envolvam castigos físicos e falas agressivas e rígidas (Barros \& Fiamenghi Jr., 2007) podem fazer com que as crianças tenham uma visão distorcida do que se constitui como cuidado, na medida em que as mesmas podem entender que essa deve ser a maneira de cuidar daqueles por quem se tem afeto. Cabe, portanto, refletir se esses profissionais têm compreensão daquilo que vêm transmitindo às crianças institucionalizadas ou se também estão reproduzindo práticas que foram passadas a eles ao longo

Tabela

Comportamentos afetivos manifestados durante as TA e TTA*.

\begin{tabular}{lc}
\hline Comportamento & Frequência \\
\hline Abraçar & $1,08 \%$ \\
Acariciar & $2,71 \%$ \\
Agredir através de gestos & $1,63 \%$ \\
Agredir fisicamente & $6,15 \%$ \\
Agredir verbalmente & $6,51 \%$ \\
Beijar & $0,00 \%$ \\
Chorar & $0,18 \%$ \\
Consolar verbalmente & $0,20 \%$ \\
Elogiar & $0,54 \%$ \\
Fazer cara de raiva/zangada(o) & $2,89 \%$ \\
Falar ou gritar conteúdo negativo & $11,75 \%$ \\
Gritar de alegria & $0,72 \%$ \\
Rir/sorrir & $65,64 \%$ \\
\hline
\end{tabular}

*Comportamentos organizados em ordem alfabética. 
de suas vidas, fora da instituição ou no exercício da profissão. Essa é uma questão delicada e difícil de ser alterada porque está baseada em crenças e costumes do meio cultural e social e que, portanto, comumente são resistentes a mudanças.

Expressões afetivas positivas apareceram em destaque nos resultados envolvendo os comportamentos afetivos, uma vez que rir/sorrir foi identificado em $67 \%$ das ocorrências como sendo praticado pelo indivíduo que iniciava a TTA ou a TA e, por vezes, vinha associado a outro como gritar de alegria e abraçar. Além disso, quando se tratava de TA, $37 \%$ dos episódios tiveram a presença desse comportamento. Por vezes, as crianças dialogavam sobre assuntos diversos, faziam piadas ou expressavam através da fala algum conteúdo cômico. Comparando-se, finalmente, as ocorrências de comportamentos positivos e negativos, percebe-se que os do primeiro tipo tiveram maiores frequências de ocorrência o que permite pensar que a análise desses comportamentos permitiu uma caracterização mais rica sobre as TTA e TA, que são o objeto desse estudo.

\section{Considerações finais}

O presente estudo se propôs a identificar e caracterizar as trocas afetivas e tentativas de trocas afetivas entre crianças e seus pares e entre elas e seus educadores, em contextos de instituições de acolhimento. Apesar da relevância teórica e social que se atribui ao tema, é surpreendente o quadro encontrado em relação à produção. A literatura sobre afetividade em crianças acolhidas é bastante escassa, o que se apresentou como um sério problema para a discussão dos resultados obtidos, sem que se tivesse evidências com as quais se pudesse contrastá-los.

De todo modo, pode-se considerar que as trocas afetivas estabelecidas entre crianças e seus pares e entre elas e seus educadores são fundamentais para o desenvolvimento de competências emocionais e de muito valor para o seu desenvolvimento global. A par de situações emocionalmente desgastantes e próprias de crianças que vivem em instituições de acolhimento, um resultado importante dessa pesquisa foi o número elevado de ocorrências do comportamento rir/sorrir, chamando também a atenção por ser bem superior ao dos demais comportamentos analisados. Especula-se que as manifestações afetivas, positivas e negativas, de outras modalidades nem sempre são tão explícitas e talvez se apresentem mais de forma reservada. Além do que, rir/ sorrir é em geral associado a alegria e bem-estar.

Outra questão que deve ser colocada em discussão é a baixa ocorrência de tentativas e trocas afetivas entre a díade criança-educador. Esse resultado é considerado preocupante, indicando a necessidade de haver uma maior atenção quanto à forma como esses profissionais compreendem a maneira de cuidar e as práticas que devem ser adotadas. Para isso, pode-se pensar em treinamentos e programas psicoeducativos que sejam realizados dentro das instituições, voltados para os educadores que já estão atuando como tal, bem como para profissionais que venham a compor o quadro de funcionários. Com isso, é possível se criar um espaço de reflexão em que seja discutido seu papel como modelos para construção da identidade e como agentes de socialização emocional.

Apesar de os substantivos avanços na legislação que trata de crianças acolhidas, ainda há pouco sendo estudado acerca da afetividade nesse contexto. Considera-se relevante o estudo mais aprofundado nessa temática com vistas ao aprimoramento do atendimento a esses indivíduos e à implementação de ações que, de fato, contribuam para o bem-estar emocional desses indivíduos.

\section{Referências}

Alexandre, D. T., \& Vieira, M. L. (2004). Relação de apego entre crianças institucionalizadas que vivem em situação de abrigo. Psicologia em Estudo, 9(2), 207-217. https://doi.org/10.1590/S1413-73722004000200007

Altmann, J. (1974). Observational study of behavior: Sampling methods. Behavior, 49(3), 227-267.

Barros, R. C., \& Fiamenghi Jr., G. A. Interações afetivas de crianças abrigadas: Um estudo etnográfico. Ciência \& Saúde Coletiva, 12(5), 1267-1276. https://doi.org/10.1590/S1413-81232007000500024

Belsky, J., \& Haan, M. (2011). Annual research review: Parenting and children's brain development: The end of the beginning. Journal of Child Psychology and Psychiatry, 52(4), 409-428. https://doi.org/10.1111/j. 1469-7610.2010.02281.x 
Calcing, J., \& Benetti, S. P. C. (2014). Caracterização da saúde mental em crianças e adolescentes em acolhimento institucional. Psico, 45(4), 559-567. https://doi.org/10.15448/1980-8623.2014.4.13629

Cavalcante, L. I. C. (2008). Ecologia do cuidado: Interações entre a criança, o ambiente, os adultos e seus pares em instituição de abrigo. Tese de Doutorado, Instituto de Psicologia, Universidade Federal do Pará, Belém, PA.

Cecílio, M. S., Borges, C. A. P., \& Scorsolini-Comin, F. (2018). Um olhar para a diversidade: Pensando as questões de gênero em um regime de coeducação nas instituições de acolhimento. In: L. I. C. Cavalcante, C. M. C. Magalhães, L. S. Corrêa, E. F. Costa, \& D. A. Cruz (Orgs.), Acolhimento institucional de crianças e adolescentes: Teorias e evidências científicas para boas práticas (pp. 113-122). Curitiba, PR: Juruá.

Corrêa, L. S., \& Cavalcante, L. I. C. (2013). Educadores de abrigo: Concepções sobre o desenvolvimento e práticas de cuidado em situação de brincadeira. Journal of Human Growth and Development, 23(3), 1-9.

Gerhardt, S. (2004). Why love matters: How afection shapes a baby's brain. New York, NY: Routledge.

Ijzendoorn, M. H., Palacios, J., Sonuga-Barke, E. J., Gunnar, M. R., Vorria, P., McCall, R. B. et al. (2011). Children in institutional care: Delayed development and resilience. Monographs of the Society for Research in Child Development, 76(4), 8-30. https:// doi.org/10.1111/j.1540-5834.2011.00626.x

Keller, H. (2007). Cultures of infancy. Mahwah, NJ: Lawrence Erlbaum.

Lyra, J., \& Medrado, B. (2000). Gênero e paternidade nas pesquisas demográficas: O viés científico. Estudos Feministas, 8(1), 145-158.

Magalhães, C. M. C., Costa, L., \& Cavalcante, L. I. C. (2011). Percepção de educadores de abrigo: O seu trabalho e a criança institucionalizada. Journal of Human Growth and Development, 21(3), 818-831.

Maia, J. M. D., \& Williams, L. C. A. (2005). Fatores de risco e fatores de proteção ao desenvolvimento infantil: Uma revisão da área. Temas em Psicologia, 13(2), 91-103.

Mendes, D. M. L. F., \& Seidl-de-Moura, M. L. (2009). O sorriso como parte da história evolutiva da espécie e os determinantes culturais. Arquivos Brasileiros de Psicologia, 61(1), 109-120.

Perucchi, J., \& Beirão, A. M. (2007). Novos arranjos familiares: Paternidade, parentalidade e relações de gênero sob o olhar de mulheres chefes de família. Psicologia Clínica, 19(2), 57-69.

Pessoa, C. C., \& Costa, L. H. F. M. (2014). Constituição da identidade infantil: Significações de mães por meio de narrativas. Revista Quadrimestral da Associação Brasileira de Psicologia Escolar e Educacional, 18(3), 501-509. https://doi.org/10.1590/2175-3539/2014/0183774

Seidl-de-Moura, M. L., \& Ribas, A. F. P. R. (2004). Evidências sobre características de bebês recém-nascidos: Um convite a reflexões teóricas. In: M. L. Seidl-de-Moura (Org.), O bebê do século XXI e a psicologia em desenvolvimento (pp. 21-59). São Paulo, SP: Casa do Psicólogo.

Siqueira, A. C., \& Dell'Aglio, D. D. (2006). O impacto da institucionalização na infância e na adolescência: Uma revisão da literatura. Psicologia \& Sociedade, 18(1), 71-80. https://doi.org/10.1590/S0102-71822006000100010

\section{Stella Rabello Kappler}

Doutoranda em Psicologia Social pela Universidade do Estado do Rio de Janeiro (UERJ). Rio de Janeiro - RJ. Brasil. Mestre em Psicologia Social (UERJ), Psicóloga pela Universidade Católica de Petrópolis (UCP). Petrópolis - RJ. Brasil. Integrante e colaboradora dos grupos de pesquisa Interação Social e Desenvolvimento e Desenvolvimento Socioemocional e Parentalidade.

E-mail: stella.rkappler@gmail.com

http://orcid.org/0000-0002-5903-9845

\section{Deise Maria Leal Fernandes Mendes}

Professora Adjunta do Instituto de Psicologia da Universidade do Estado do Rio de Janeiro (UERJ). Rio de Janeiro - RJ. Brasil. Doutora e Mestre em Psicologia Social pela Universidade do Estado do Rio de Janeiro (UERJ). Rio de Janeiro - RJ. Brasil. Líder dos grupos de pesquisa Interação Social e Desnvolvimento e Desenvolvimento Socioemocional e Parentalidade. 
E-mail: deisefmendes@gmail.com

(iD) http://orcid.org/0000-0003-3487-7284

Recebido 25/08/2017

Aceito 10/09/2018

Received 08/25/2017

Approved 09/10/2018

Recibido 25/08/2017

Aceptado 10/09/2018

Como citar: Kappler, S. R., \& Mendes, D. M. L. F. (2019). Trocas afetivas de crianças em acolhimento institucional. Psicologia: Ciência e Profissão, 39, 1-13. https://doi.org/10.1590/1982-3703003184527

How to cite: Kappler, S. R., \& Mendes, D. M. L. F. (2019). Affective Exchanges of Children in Institutional Care. Psicologia: Ciência e Profissão, 39, 1-13. https://doi.org/10.1590/1982-3703003184527

Cómo citar: Kappler, S. R., \& Mendes, D. M. L. F. (2019). Intercambios Afectivos de Niños en Acogida Institucional. Psicologia: Ciência e Profissão, 39, 1-13. https://doi.org/10.1590/1982-3703003184527 